\title{
STIFFNESS PREDICTION FOR BOLTED MOMENT- CONNECTIONS IN COLD-FORMED STEEL TRUSSES
}

\author{
Apai Benchaphong ${ }^{1}$ - Rattanasak Hongthong ${ }^{1}$ - Sutera Benchanukrom² - Nirut Konkong $^{3 *}$
}

\author{
${ }^{1}$ Department of Civil Engineering, Faculty of Engineering, Rajamangala University of Technology Krungthep, \\ Bangkok, Thailand \\ ${ }^{2}$ Department of Industrial Construction Technology, Faculty of Agricultural Technology and Industrial Technology, \\ Phetchabun Rajabhat University, Phetchabun, Thailand \\ ${ }^{3}$ P.A.I.R Engineering Co., Ltd, Bangkok, Thailand
}

\begin{tabular}{l}
\hline ARTICLE INFO \\
\hline Article history: \\
Received: 1.3 .2019$. \\
Received in revised form: 10.4 .2019$. \\
Accepted: 12.4 .2019$. \\
\hline Keywords: \\
cold-formed steel \\
finite element analysis \\
elastic rotational stiffness \\
semi-rigid connection
\end{tabular}

DOI: https://doi.org/10.30765/er.1428

\begin{abstract}
:
The purpose of this research was to study the behavior of coldformed steel cantilever truss structures. A cantilever truss structure and bolt-moment connection were tested and verified by the $3 D$ finite element model. The verification results showed a good correlation between an experimental test and finite element analysis. An analytical method for elastic rotational stiffness of boltmoment connection was proposed. The equation proposed in the analytical method was used to approximate the elastic rotational stiffness of the bolt group connection, and was also applied to the Richard-Abbott model for generating the nonlinear momentrotation curve which modeled the semi-rigid connection stiffness. The 2D-finite element analysis was applied to study the behavior of the truss connection, caused by semi-rigid connection stiffness which caused a change of force to the truss elements. The results showed that the force in the structural members increased by between 13.62\%-74.32\% of the axial forces, and the bending moment decreased by between 33.05\%-100\%. These results strongly suggest that the semi-rigid connection between coldformed steel cantilever truss structures should be considered in structural analysis to achieve optimum design, acknowledging this as the real behavior of the structure.
\end{abstract}

\section{Introduction}

Cold-formed steel has seen increased usage as the primary members for residential and multi-story commercial buildings. Durability, strength, material consistency, and ecological concerns have encouraged engineers to use these structures [1-8]. Guidance for cold-formed steel structures design can be found in several design recommendations [9-11]. The codes of practice on connections between cold-formed steel sections are presented by the load capacity of the individual fastener. However, we suggest that considering load capacity only as the reference guidance is just a superficial suggestion. Practically, cold-formed steel truss connections are idealized as being either pinned or rigid, but structural analysis based on the pinned or rigid assumption does not represent the real behavior of truss connections. Dubina [12-13] and Yu et al. [14] were the earliest researchers on cold-formed steel truss connections and expressed concerns about the rigid and semi-rigid strength assumptions on connection behavior. They found that the rigid assumption was not appropriate to the strength and deformation behavior of real cold-formed steel connections. Subsequent research showed that localized in-plane elongation of the bolt-holes, due to bearing against the bolt [15-16], tilting and slippage by the hole-clearance [17] found in the bolt-moment connection, are the major cause of inconsistency between the rigid strength assumption and the behavior of real structures. The definition of a semi-rigid connection was classified as a simple connection and too flexible to qualify as rigid, but was not pinned [18].

\footnotetext{
${ }^{*}$ Corresponding author

E-mail address: nirut.k@ku.th
} 
The failure mode of cold-formed steel bolt-moment connections has been investigated by the experimental testing which was conducted on the connection between beam-column sub-frames structures in which the bearing failure mode occurred in the section web around the bolt hole [19]. As well, previous studies addressed the flexibility behavior of the cold-formed steel moment connection, based on the single lap shear bolt connection, by physical testing and by theoretical analysis, as applied to the rotational stiffness questions [2021]. Some of the equations defined by these researchers, relevant to the practical design method, were applied in practical research in a parametric study of cold-formed steel connections with different bolt diameters [22]. In all the previous studies, the research focused on the rotational stiffness of the single lap shear bolt connection. However, this may be workable in truss structures, but it is not shown in real structure behavior. To analyze and design a structure, structural engineers need to include the true behavior of connection through moment-rotation curves in analysis packages. The magnitude of the maximum axial load and the bending moment may be changed causing a reduction in the members' size. Getting the true moment-rotation curves, we need mathematical techniques to represent the relationship between a moment and curvature.

Given this problem, the present study investigated the effect of the rotational stiffness of semi-rigid connections on cantilever trusses. The research method applied was investigation by the experimental test, finite element analysis (FEA) and an analytical method applying equations that were developed in the research process. A full-scale cantilever truss was constructed to examine the ultimate load capacity and failure mode of the truss structure. The moment capacity and rotational angle of the bolt-moment specimens were also measured. All test results were verified by the 3D-finite element analysis. An analytical method for predicting the elastic rotational stiffness of a moment was proposed applying the Richard and Abbott mathematical model [23], and a 2D-finite element model was used to examine the internal forces of the truss elements.

\section{Experimental investigation}

The experimental tests were divided into two parts; a full-scale cantilever truss test and a bolt-moment connection test. All the specimens were prepared from G550-cold-formed lipped channel sections (C-102 x 51 $\mathrm{x} 12.5 \times 1.0 \mathrm{~mm})$. The truss connections were assembled by grade 8.8 steel bolt with $5 \mathrm{~mm}$ diameter. The properties of the cold-formed steel material (Table 1) and steel bolts (Table 2) were in accordance with ASTM Standards [24-25].

The truss structure specimens were $3.0 \mathrm{~m}$ long (L), and $0.5 \mathrm{~m}$ depth (D) (Figure 1(a)). Bolt, nut and washers were assembled by hand without the bolt preload.

Table 1. Material properties of cold-formed steel, G550-1T.

\begin{tabular}{ccccccccc}
\hline Item & CT-1 & CT-2 & CT-3 & CT-4 & CT-5 & Mean & SD & COV \\
\hline $\mathrm{T}(\mathrm{mm})$. & 1.045 & 1.045 & 1.044 & 1.045 & 1.045 & 1.04 & 0.0004 & 0.04 \\
$\mathrm{~W}(\mathrm{~mm})$. & 12.64 & 12.65 & 12.59 & 12.58 & 12.52 & 12.59 & 0.0522 & 0.41 \\
$F_{y}(\mathrm{MPa})$. & 608.47 & 605.77 & 605.90 & 617.50 & 606.46 & 608.82 & 4.9715 & 0.81 \\
$F_{u}(\mathrm{MPa})$. & 627.00 & 622.50 & 625.50 & 630.00 & 620.00 & 625.00 & 3.8890 & 0.62 \\
$\boldsymbol{E}_{c}(\mathrm{GPa})$. & 213.51 & 213.49 & 213.49 & 213.58 & 213.58 & 213.53 & 44.1757 & 0.02 \\
$\boldsymbol{F}_{u} / \boldsymbol{F}_{y}$ & 1.03 & 1.02 & 1.03 & 1.02 & 1.02 & 1.02 & 0.0054 & 0.53 \\
\hline
\end{tabular}

Table 2. Material properties of bolts.

\begin{tabular}{ccccccccc}
\hline Item & BT-1 & BT-2 & BT-3 & BT-4 & BT-5 & Mean & SD. & COV \\
\hline$d .(\mathrm{m})$. & 4.93 & 4.97 & 4.97 & 4.97 & 4.94 & 4.95 & 0.019 & 0.393 \\
$F_{y}$ (MPa.) & 930.00 & 949.00 & 927.00 & 976.00 & 872.00 & 930.80 & 38.232 & 4.107 \\
$F_{u}$ (MPa.) & 963 & 930 & 963 & 997 & 909 & 952.40 & 33.908 & 3.560 \\
$E_{b}$ (GPa.) & 204.08 & 204.08 & 204.09 & 204.10 & 204.09 & 204.08 & 7.385 & 0.003 \\
\hline
\end{tabular}



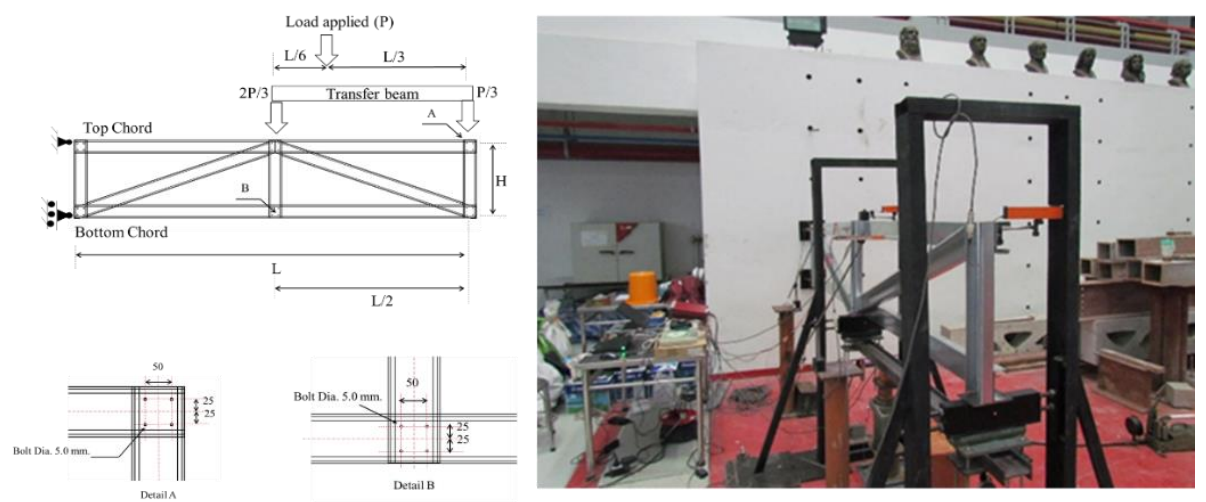

(a)

(b)

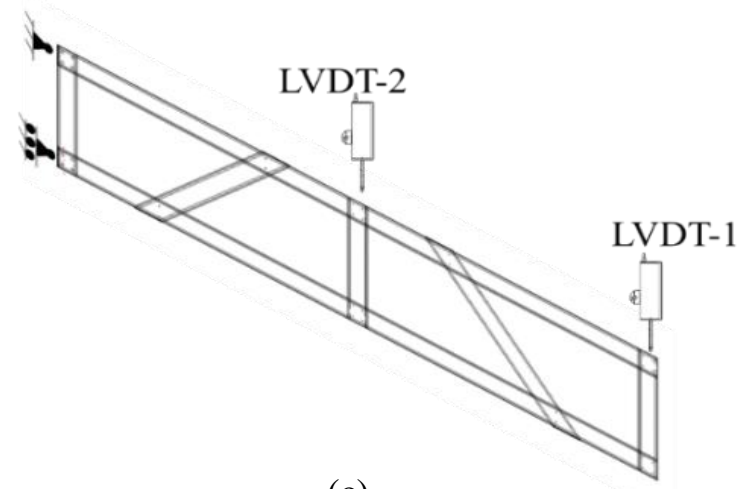

(c)

Figure 1. Test setup (a) Examined truss model, (b) test set up, and (c) LVDT monitoring points.

The truss specimen was set up in a test apparatus skeleton. Lateral support of the top chord was provided by a roller linked to the skeleton frame.

The truss specimen was flipped and load applied from the laboratory floor. The concentrated load from the load cell was applied to the transfer beam and distributed to the joint of the top chord member (Figure 1(b)). The vertical deformation of the truss structure was measured by the linear variable differential transformers (LVDT) which were installed at the joint of the top chord member (Figure 1(c)). The load cell and LVDT were connected to the data acquisition system, with computer monitoring. The failure of the specimen was defined as the point at which the truss showed plastic deformation behavior. Once the applied load began to drop, even though the specimen maintained vertical deformation, the test was stopped.

The bolt-moment connection specimen (Figure 2(a)) was statically loaded with the parameters illustrated in Figure 2(b). Bolts and nuts were assembled with integral washers that were tightened by hand. Slipping of the connection after initial loading was allowed. 


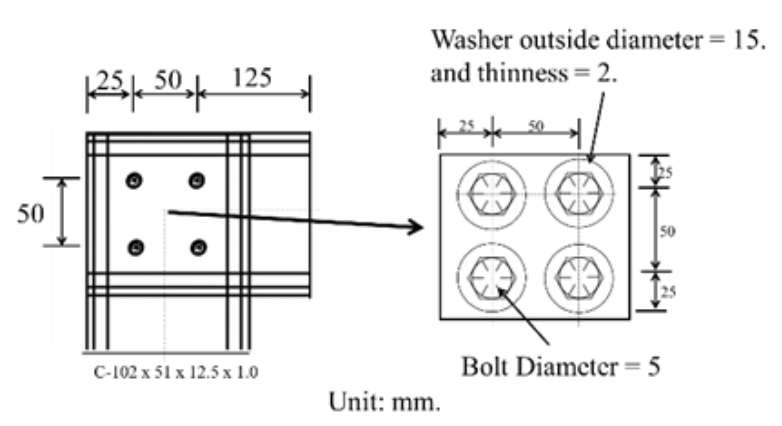

(a)

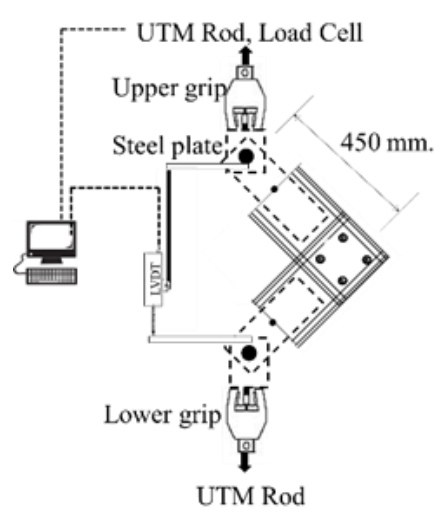

(c)

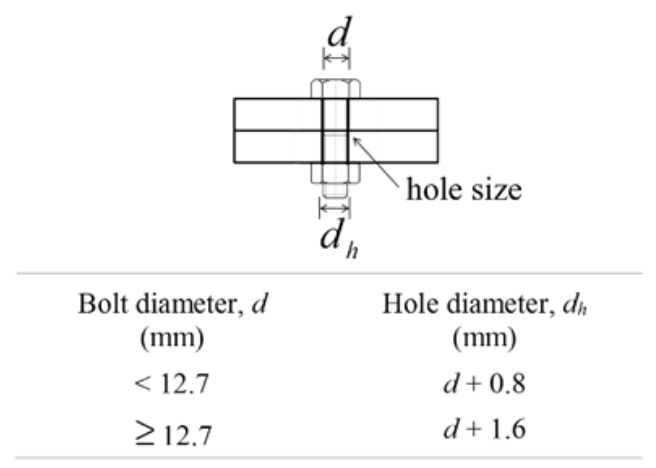

(b)

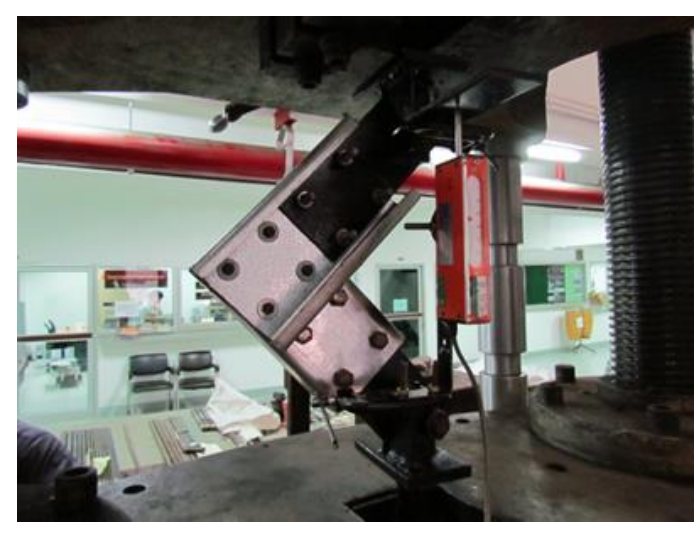

(d)

Figure 2. Bolt connection specimens and test setup (a) Bolt connection geometries, (b) hole size, (c) test apparatus, and $(d)$ test specimen.

The tests were set up on a universal testing machine (UTM) (Figure 2 (c-d)) in which the load cell and the LVDT were used to monitor the load-deformation behavior of the connection. The tension load was applied to the specimen using a displacement control with a speed of 1 millimeter/minute. The failure of the specimen was defined as the first appearance of plastic deformation of the specimen, and the test was immediately stopped, even though the applied load began to drop and the specimen proceeded to a large deformation.

\section{Finite element validation}

The finite element analysis was divided into 2 types; a three-dimension analysis (3D) and two-dimensional analysis (2D). In the 3D analysis, the ANSYS finite element program [26] was used for the simulations of the truss structure and bolt-moment connections (Figure 3). SHELL281 is 8-node with 6-degrees of freedom at each node shell element which modeled the cold-formed steel (Figure 3(c). SOLID186 is 3-D 20-node with 3degrees of freedom at each node solid element which modeled the steel bolts and washers (Figure 3(d)). The contact problems of the bolt-to-cold-formed steel (bolt-hole) contact and the washer-to-cold-formed steel contact were modeled. The contact elements (CONTAC174 and TARGE170) and a pure penalty contact algorithm were used to solve the constrained optimization problem (Figure 3 (e-f)). 


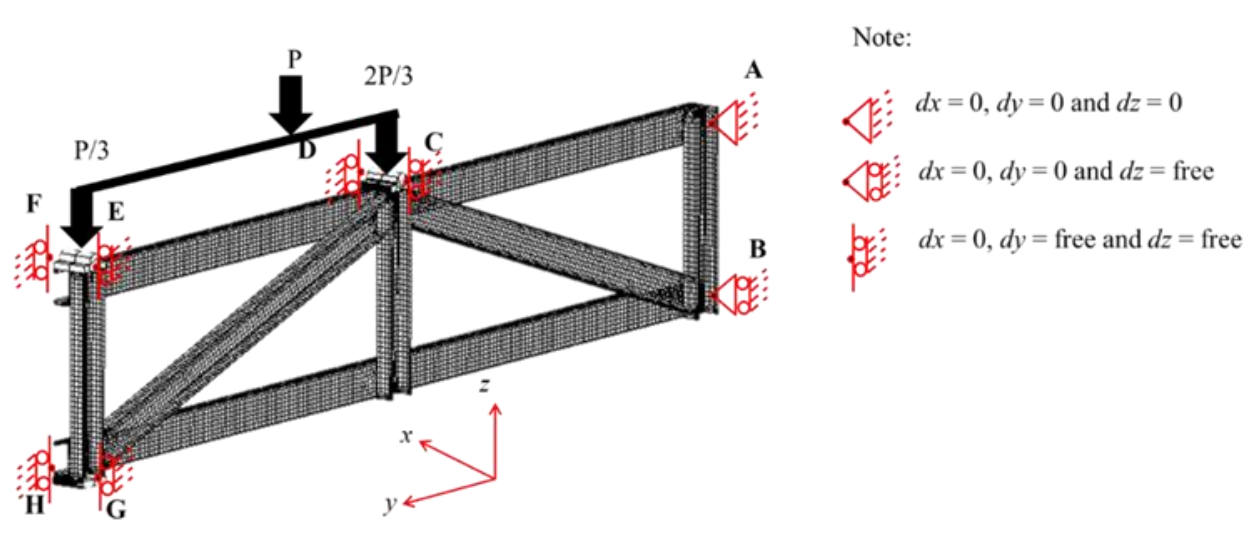

(a)
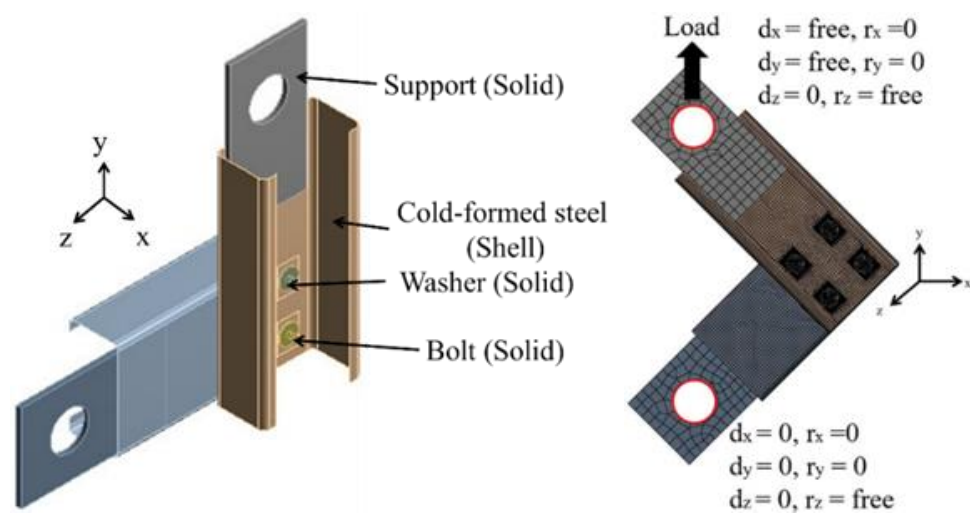

(b)

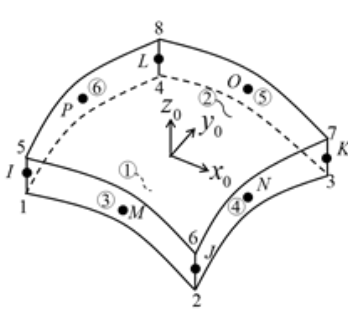

(c)

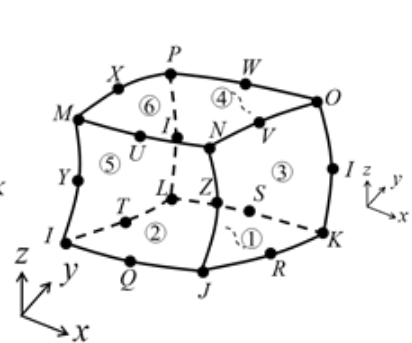

(d)

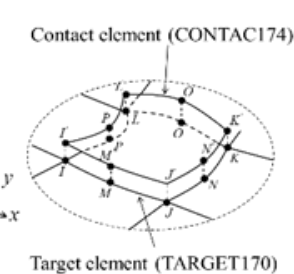

(e)

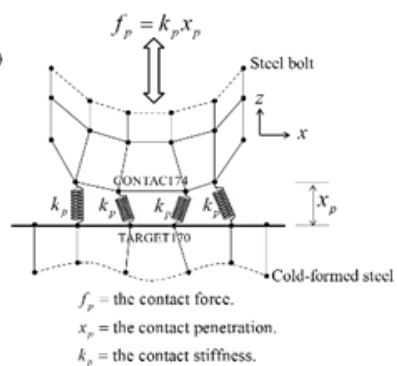

(f)

Figure 3. Geometry and element type and material model of FEA (a) Truss geometry model, (b) Connection geometry model, (c) SHELL281), (d) SOLID181, (e) contact element, and (f) pure penalty algorithm.

The mesh size was controlled by the aspect ratios (length-to-width ratio) which selected to be close to 1.0 for the cold-formed steel, bolts, and washers. Surrounding the holes, refinement of the mesh size was generated as necessary to achieve the accuracy of stress links between the bolt and the bolt-hole elements [27]. The static friction between the steel plates was neglected.

A linear elastic stress-strain relationship was assumed for the steel bolt. The test results of the material properties of the cold-formed steel, test stress $\left(\sigma_{\text {test }}\right)$ and strain $\left(\varepsilon_{\text {test }}\right)$, were converted to true stress $\left(\sigma_{\text {true }}\right.$ ) and strain $\left(\varepsilon_{\text {true }}\right)$ by Eq. (1), which then were placed into the multi-linear isotropic hardening material model. The Poisson ratio used was 0.3 for every steel material. The Large Deflection assumption was applied to analyze the behavior of the cantilever truss structures and the bolt-moment connections. 


$$
\sigma_{\text {true }}=\sigma_{\text {test }}\left(1+\varepsilon_{\text {test }}\right), \varepsilon_{\text {true }}=\ln \left(1+\varepsilon_{\text {test }}\right)
$$

In the 2D analysis, SAP2000 [28], static analysis was applied to analyze the force in the truss elements with reference to the truss geometry of the full-scale cantilever truss specimens (Figure 1(a)).

The truss connection was modeled as a rotational spring element inserted at the intersection point between the members in the joints (Figure 4 (a). A frame element with a plastic link element was used to model the truss elements (Figure 4 (b). The plastic link element property was specified in the force-deformation relationships for the axial deformation, shear deformation and rotation deformation (Figure 4 (c)). In this study, the 2D analysis focused on the semi-rigid connection behavior in the truss, thus only the rotational spring stiffness was considered in the analysis model. The stiffness of the axial and shear components was assumed as being rigid behavior. A linear elastic stress-strain relationship was assumed for the cold-formed steel material (Table 1).

\section{Experimental test and finite element results}

The experimental results of the test were compared by finite element analysis of the failure mode and loaddeformation curve (Figure 5). The failure mode of the cantilever truss specimens was a connection failure mode (Figure 5(a)) in which the vertical load-displacement curves of 2-LVDT represented the maximum capacity of the truss (Figure 5(b)). At the $110 \mathrm{~mm}$ of LVDT-1 and $83 \mathrm{~mm}$ of LVDT-2, the vertical load capacity of the truss was measured as $5.571 \mathrm{kN}(2 \mathrm{P} / 3+\mathrm{P} / 3)$.

For the bolt-moment test, the moment capacity $\left(M_{\text {test }}\right)$ and rotation deformation $(\phi)$ were calculated by the Law of Cosine (Figure 6) represented by Eq. (2-3).

$$
\begin{gathered}
M_{\text {test }}=P_{\text {test }} e \sin \theta \\
\phi=\left[\cos ^{-1}\left(\frac{a^{2}-b^{2}-c^{2}}{2 b c}\right)-90\right] \frac{\pi}{180^{\circ}}(\text { Radian })
\end{gathered}
$$

where $P_{\text {test }}$ is an applied force, $e$ is a moment arm, $\theta$ is an angle of applied force which spins out of the centroid, and $a, b$ and $c$ are the lengths of the legs of a triangle.

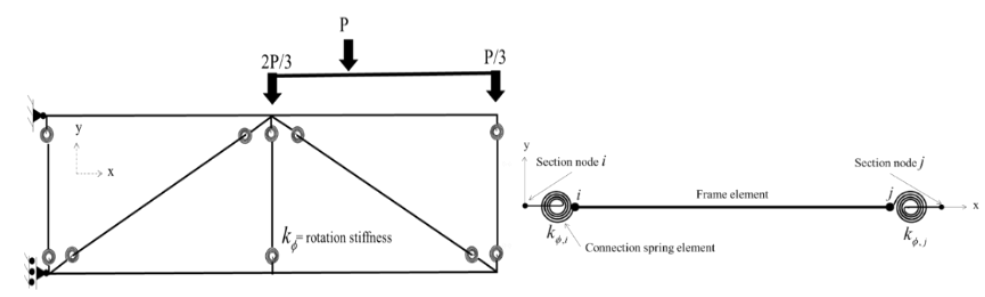

(a)

(b)

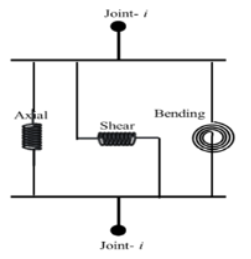

(c)

Figure 4. Truss geometry (a) Semi-rigid connection truss structure, (b) frame element with semi-rigid connections, and (c) Link element. 


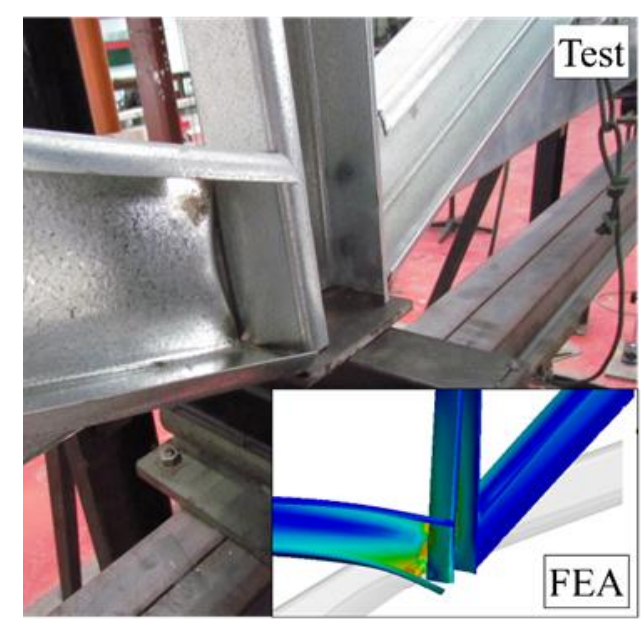

(a)
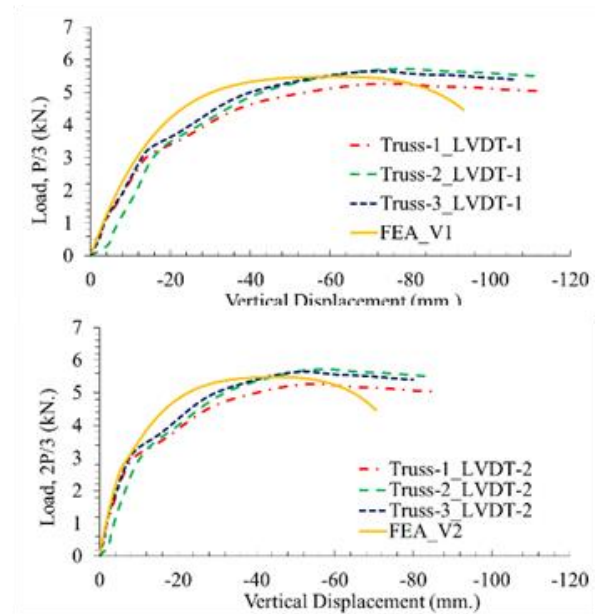

(b)

Figure 5. Results of the test and finite element models (a) The truss failure, and (b) Load and vertical displacement curve.

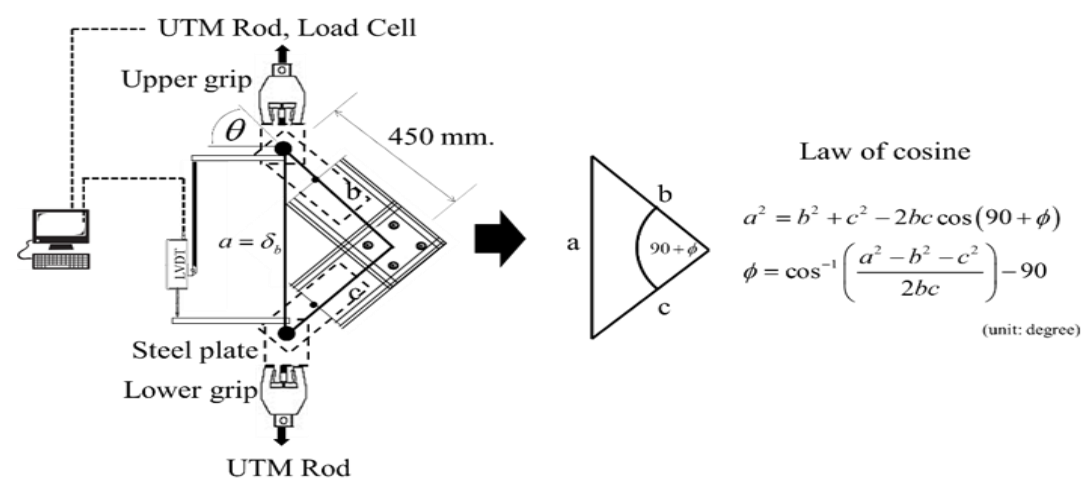

Figure 6. Moment and rotation angle of the experimental test.

The bearing failure mode of the bolt-hole was found in the tests and the finite element model (Figure 7(a)). The ratio of the ultimate loads between the experiment results and FEA ( $M_{\text {test }} / M_{\text {FEA }}$ ) shows that the momentrotation curves from the FEA were in good correlation with the experimental results (Figure 7(b) and Table $3)$.

\section{Semi-rigid connections stiffness and 2D-finite element analysis}

For the 2D-finite element analysis, the frame element with a plastic link at the ends was modeled for analyzing the internal force of cantilever truss element. Only rotational stiffness was considered in the finite element model in which shear stiffness and axial stiffness in the joint model were assumed as rigid behavior. Richard and Abbott [23] proposed the mathematical model for semi-rigid connections which can be used to represent the nonlinear relationship of a connection as given in Eq. (4) (Figure 8). The elastic rotational stiffness was a major parameter that influences the characteristics of the mathematical model. 


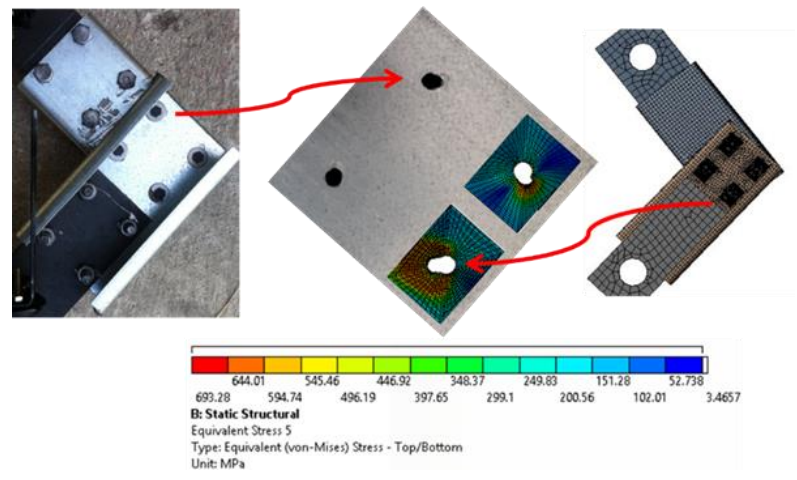

(a)

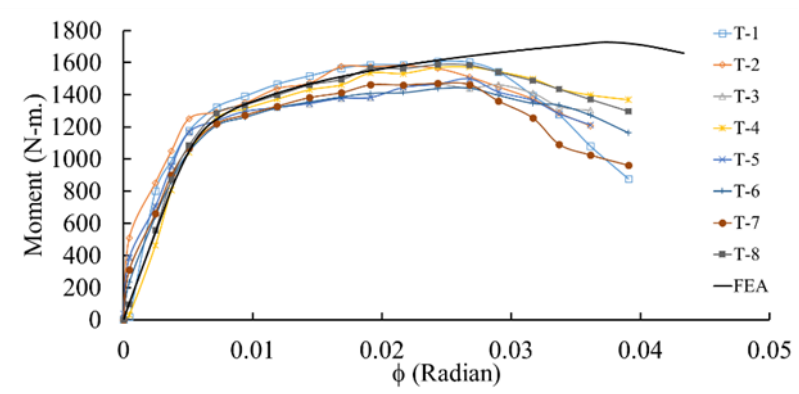

(b)

Figure 7. Bolt-moment connection results (a) The failure mode of bolt-moment connection, and (b) load-deformation curves.

Table 3. Summarization of the lap shear connection results.

\begin{tabular}{cccc}
\hline Test & Moment capacity, $M_{\text {test }}$ & Failure mode & $M_{\text {test }} / M_{\text {FEA }}$ \\
\hline 1 & 1607.70 & Bearing & 1.04 \\
2 & 1581.57 & Bearing & 1.02 \\
3 & 1466.75 & Bearing & 0.95 \\
4 & 1573.02 & Bearing & 1.02 \\
5 & 1499.74 & Bearing & 0.97 \\
6 & 1441.70 & Bearing & 0.93 \\
7 & 1471.11 & Bearing & 0.95 \\
8 & 1588.26 & Bearing & 1.03 \\
Fean & 1528.73 & & 0.99 \\
\hline
\end{tabular}

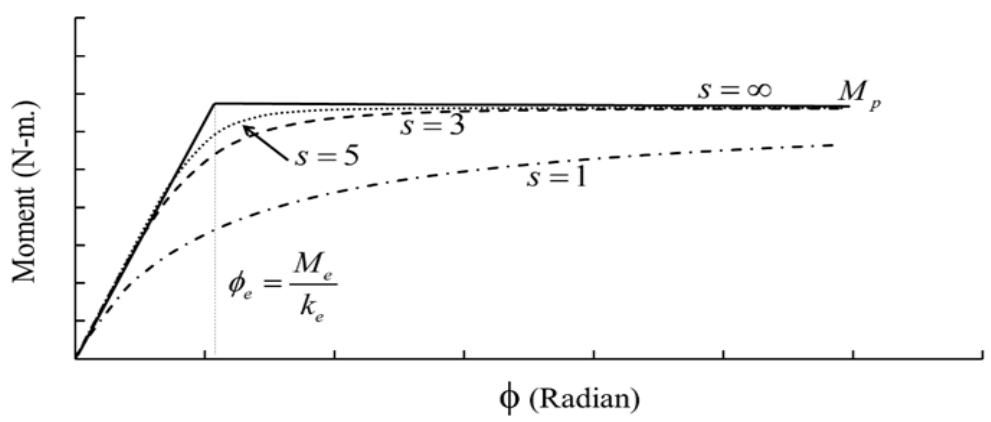

Figure 8. Richard and Abbott curves [23].

$$
M=\frac{k_{e} \phi}{\left[1+\left(\phi / \phi_{e}\right)^{s}\right]^{1 / s}}
$$

where $M$ is the moment capacity of the connection, $\phi$ is the rotation of the connection, $k_{e}$ is the elastic rotational stiffness or elastic stiffness, $\phi_{e}$ is the reference plastic rotation given by $\phi_{e}=M_{e} / k_{e}, M_{e}$ is the elastic moment capacity of the connection and $s$ is the shape parameter of the curve $(0>s \geq \infty)$. 
In this study, the analytical procedure was used to analyze the elastic rotational stiffness of the bolt-moment connection. The analysis included the effect of the bearing stiffness due to a bolt-plate bearing deformation, and shear stiffness due to shear force, along the line of the bolt group region. The resulting forces of boltmoment connection were idealized, as illustrated in Figure 9. The force in the bolt was induced by the bending moment at the centroid of the bolt group (Figure 9 (b)).

The elastic rotational stiffness was calculated based on the relationship of the elastic moment $\left(M_{e}\right)$ and the elastic rotation $\left(\phi_{e}\right)$ at the centroid of the bolt group, which can be written as Eq. (5).

$$
k_{e}=\frac{M_{e}}{\phi_{e}}=\frac{\sum_{i=1}^{n} F_{i} r_{i}}{\phi_{e, b}+\phi_{e, s}}
$$

where $F_{i}$ is the force in the bolt, $r_{i}$ is the distance from the center of rotation to the bolt, $n$ is the number of bolts in the bolt-group, $\phi_{e, b}$ is the elastic bearing rotation due to the bolt-plate interaction, $\phi_{e, s}$ is the elastic shear rotation due to the shear force along the line of the bolt group region.

In the analysis procedure, the force in the bolt can be calculated by the nominal bearing capacity of the bolt connection which was proposed in AISI-S100 [9].

$$
F_{i}=C m_{f} d t F_{u}
$$

where $t$ is the thickness of the cold-formed steel, $d$ is the nominal bolt diameter, $F_{u}$ is the tensile strength of the cold-formed steel, $C$ is the bearing factor $[9,29]$ and $m_{f}$ is the modification factor for the type of bearing connection.

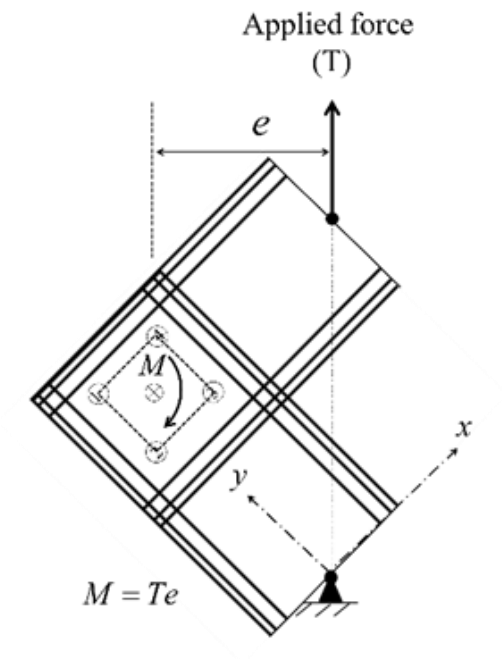

(a)

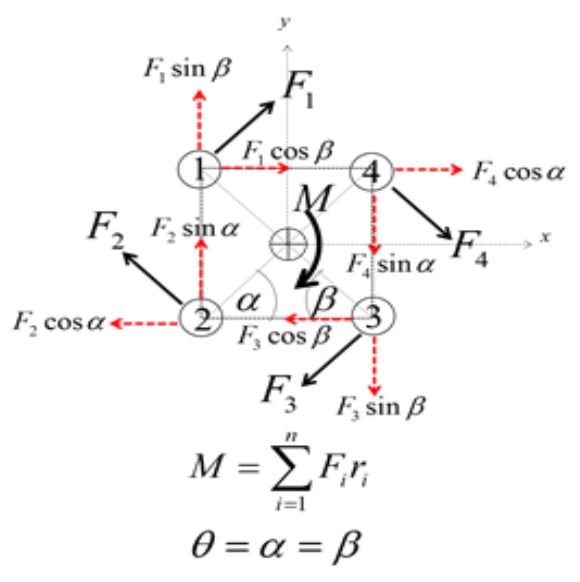

(b)

Figure 9. Force components in the bolt at the bolt group region (a) Connection model, and (b) forces in the bolt.

The elastic bearing rotation was considered on the interaction between the bolt and the hole (Figure 10) which was determined by Eq. (7). 


$$
\phi_{e, b}=\frac{\sum_{i=1}^{n} \delta_{i}}{\sum_{i=1}^{n} r_{i}}
$$

where $\delta_{i}$ is the deformation of the bolt-plate interaction (Eq. (8) and bolt-plate interaction stiffness Eq.(8b)[30].

$$
\delta_{i}=\frac{\sum_{i=1}^{n} F_{i}}{\sum_{i=1}^{n} k_{b p, i}}
$$

with

$$
\begin{aligned}
& \frac{1}{k_{b p}}=\frac{3 t_{1}^{2}+16 t_{2}^{2} t_{2}+16 t_{1} t_{2}^{2}+3 t_{2}^{3}}{128 E_{b} I_{b}} \\
& +\frac{3}{8} \frac{\left(t_{1}+t_{2}\right)}{\kappa A_{b} G_{b}}+\left(\frac{1}{t_{1} E_{b}}+\frac{1}{t_{2} E_{b}}\right) \\
& +\left(\frac{1}{t_{1} E_{p 1}}+\frac{1}{t_{2} E_{p 2}}\right)
\end{aligned}
$$

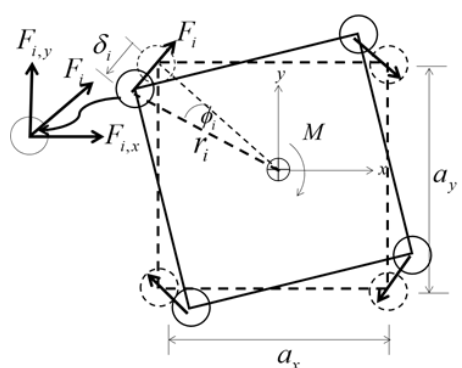

(a)

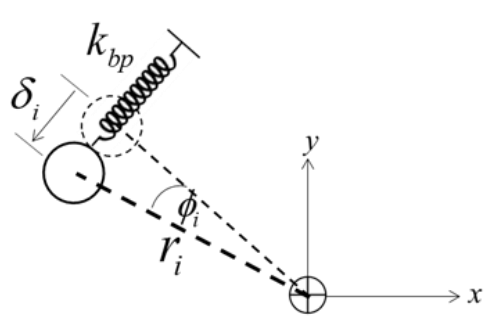

(b)

Figure 10. Bearing stiffness model (a) Force and deformation at each bolt-hole, and (b) bearing stiffness and rotation.

The resultant elastic bearing rotation can be rewritten as Eq. (9).

$$
\phi_{e, b}=\frac{\sum_{i=1}^{n} \delta_{i}}{\sum_{i=1}^{n} r_{i}}=\frac{\sum_{i=1}^{n} F_{i}}{\sum_{i=1}^{n} r_{i} k_{b p, i}}=\frac{\sum_{i=1}^{n}\left(C m_{f} d t F_{u}\right)_{i}}{\sum_{i=1}^{n} r_{i} k_{b p, i}}
$$

The rotation due to the shear force along the line of the bolt group region (Figure 11(a)) was induced by the vector force in the bolt which can be considered by Eq. 10 . 


$$
V_{1}\left(\frac{a_{y}}{2}\right)+V_{2}\left(\frac{a_{x}}{2}\right)+V_{3}\left(\frac{a_{y}}{2}\right)+V_{4}\left(\frac{a_{x}}{2}\right)=M_{e}
$$

where $V_{1}, V_{2}, V_{3}$ and $V_{4}$ are the shear forces in the bolt group region (Figure.11(a)).

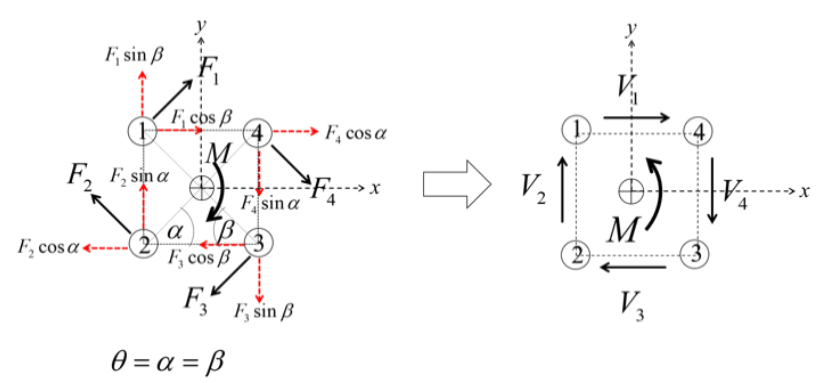

(a)

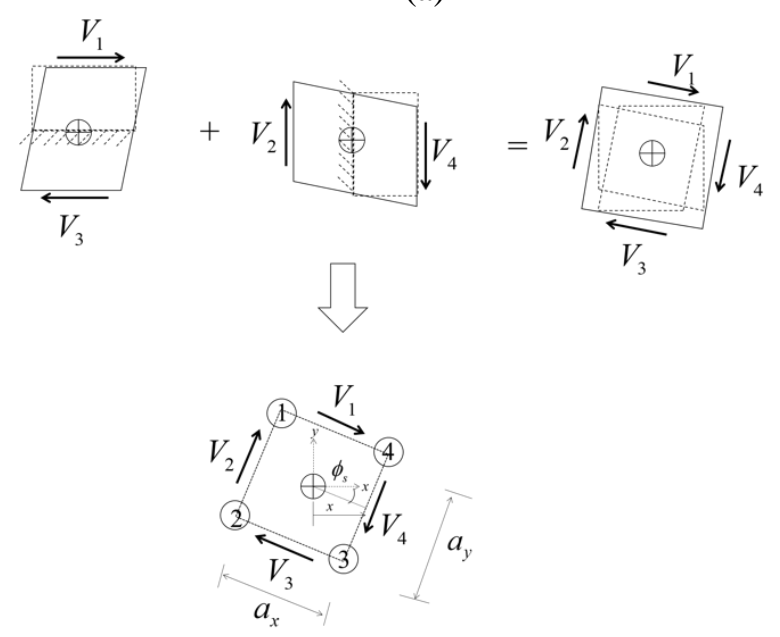

(b)

Figure 11. Shear force components of the bolt group region. (a) Shear components; (b) the cantilever beam with a shear force at the end assumption.

In the case of the symmetrical arrangement of the bolts on both the $\mathrm{x}$-axis and $\mathrm{y}$-axis, the bolt force was shared equally on each of the bolts. The shear force distribution at the bolt group region was considered by using the average shear force $(V)$. Thus, Eq. (10) was rewritten as Eq. (11), and the shear force on the bolt group region can be written as Eq. (12).

In the case of the symmetrical arrangement of the bolts on both the x-axis and $y$-axis, the bolt force was shared equally on each of the bolts. The shear force distribution at the bolt group region was considered by using the average shear force $(V)$. Thus, Eq. (10) was rewritten as Eq. (11), and the shear force on the bolt group region can be written as Eq. (12).

$$
\begin{gathered}
V\left(a_{x}+a_{y}\right)=M_{e} \\
V=\frac{M_{e}}{a_{x}+a_{y}}
\end{gathered}
$$


The bolt group region was assumed to be a cantilever beam with the assumption of shear force at the end of the beam (Figure 11 (b)). The superposition method was used to incorporate the shear rotation deformation. Using basic beam theory, the moment along a bolt group region is equal to the area under the shear force curve, and can be written as Eq. 13 .

$$
V(x)=\frac{d M}{d x}=(E I)_{b r} \frac{d^{3} y(x)}{d x^{3}}=\frac{M_{e}}{a_{x}+a_{y}}
$$

Thus,

$$
\begin{aligned}
M(x) & =\int V(x) d x \\
& =(E I)_{b r} \int \frac{M_{e}}{a_{x}+a_{y}}=\frac{M_{e} x}{a_{x}+a_{y}}+c_{1} \\
\phi(x) & =\int M(x) d x \\
& =(E I)_{b r} \frac{M_{e} x^{2}}{2\left(a_{x}+a_{y}\right)}+c_{1} x+c_{2}
\end{aligned}
$$

where $(E I)_{b r}$ is the flexural rigidity of the bolt group region and $c_{1}$ and $c_{2}$ are integration constants. The possible boundary conditions are calculated by Eq. (14).

The possible boundary conditions are calculated by Eq. (14).

$$
M_{x}(0)=0 \text { and } \phi_{x}(0)=0
$$

Using these boundary conditions, the rotation of the bolt group region due to shear force can be written as Eq. (15).

$$
\phi_{e, s}=\left(\frac{M_{e}}{2\left(a_{x}+a_{y}\right)(E I)_{b r}}\right) x^{2}
$$

Finally, the elastic rotational stiffness of the bolt-group can be written as Eq. (16).

$$
k_{e}=\frac{M_{e}}{\phi_{e}}=\frac{\sum_{i=1}^{n} F_{i} r_{i}}{\frac{\sum_{i=1}^{n} F_{i}}{\sum_{i=1}^{n} r_{i} k_{b p, i}}+\left(\frac{M_{e}}{2\left(a_{x}+a_{y}\right)(E I)_{b r}}\right) x^{2}}
$$

The proposed elastic rotational stiffness was compared by FEA, the experimental test and the Lim and Nethercot equation [15]. The comparison of the load-deformation curves are shown in Figure 12. 


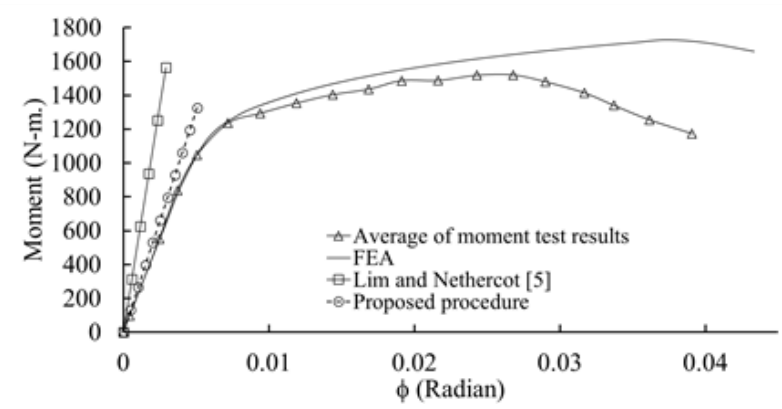

(a)

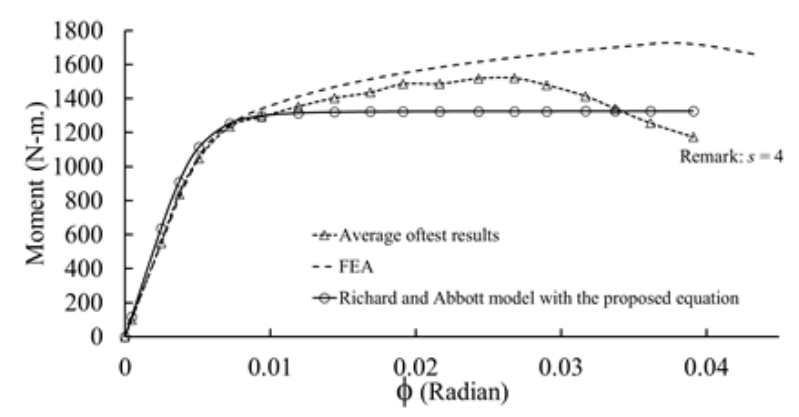

(b)

Figure 12. Comparison results (a) the proposed equation with tests, FEA, and previous model, and (b) the curve of the Richard and Abbott model with the proposed equation with the tests and FEA.

The results show that the proposed equation demonstrates good correlation between the experimental results, FEA, but were lower than the results calculated by the Lim and Nethercot equation [15]. The simplified Richard and Abbott equation [23] also includes the proposed elastic rotational stiffness equation as shown in Figure 12(b).

For the application of the proposed equation, the curve of the Richard and Abbott model from the proposed equation, shown in Figure 12(b), was assigned to the rotational spring model which was embedded at the position of the joints in a global cantilever truss model (Figure 13).

The applied load refers to the maximum capacity of the truss structure from the experiment results (refer to Figure 5). The changing internal forces in the truss element, due to it being a semi-rigid joint, were compared to the forces in a truss element with a rigid joint. The 2D-finite element results showed that the axial forces in the truss elements increased by $13.62 \%-74.32 \%$, and some elements of the axial forces decreased by 16.17 $100 \%$ (Figure 14). The bending moment decreased by 33.05-100\% (Figure 15).

The comparison of the 2D finite element analysis results between the truss elements with the semirigid joint and those with the rigid joint show the effect of the semi-rigid connections on the structural system that exhibit the changing of force from the structural members (Table 4).

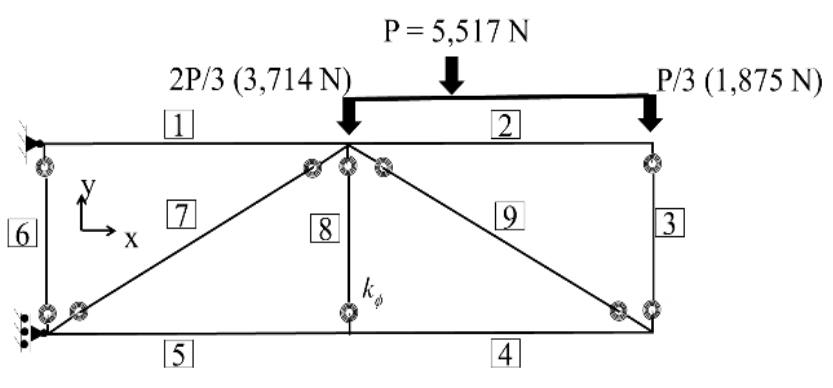

(a)

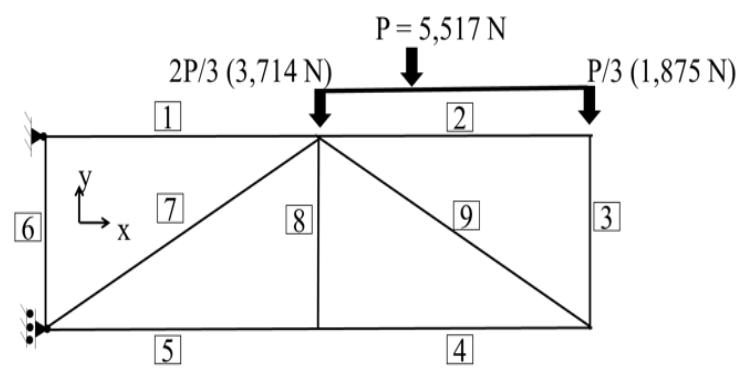

(b)

Figure 13. Diagram of a cantilever truss structure (a) semi-rigid joint stiffness truss, and (b) rigid joint stiffness truss. 
Table 4. Comparison of force in the truss element.

\begin{tabular}{|c|c|c|c|c|c|c|c|}
\hline \multirow[b]{2}{*}{ Frame } & \multicolumn{3}{|c|}{ Rigid joint truss } & \multicolumn{2}{|c|}{ Semi-rigid joint truss } & \multicolumn{2}{|c|}{$\%$ difference } \\
\hline & $\begin{array}{c}\text { Station } \\
(\mathrm{m})\end{array}$ & $\begin{array}{c}\text { Axial } \\
(\mathrm{kN})\end{array}$ & $\begin{array}{c}\text { Moment } \\
(\mathrm{kN}-\mathrm{m})\end{array}$ & Axial (kN) & $\begin{array}{c}\text { Moment } \\
(\mathrm{kN}-\mathrm{m})\end{array}$ & $\begin{array}{c}\text { Axial } \\
(\%)\end{array}$ & $\begin{array}{c}\text { Moment } \\
(\%)\end{array}$ \\
\hline \multirow{2}{*}{1} & 0.00 & 16.07 & -1.30 & 22.28 & 0.00 & 38.65 & -100.00 \\
\hline & 1.50 & 16.07 & 0.31 & 22.28 & 0.21 & 38.65 & -33.05 \\
\hline \multirow{2}{*}{2} & 0.00 & 0.89 & -0.23 & 0.00 & -0.10 & -100.00 & -58.29 \\
\hline & 1.50 & 0.89 & 0.19 & 0.00 & 0.00 & -100.00 & -100.00 \\
\hline \multirow{2}{*}{3} & 0.00 & -1.58 & 0.19 & -1.79 & 0.00 & 13.62 & -100.00 \\
\hline & 0.50 & -1.58 & -0.26 & -1.79 & 0.00 & 13.62 & -100.00 \\
\hline \multirow{2}{*}{4} & 0.00 & -4.25 & 0.17 & -5.67 & 0.08 & 33.50 & -54.96 \\
\hline & 1.50 & -4.25 & -0.29 & -5.67 & 0.07 & 33.50 & -122.47 \\
\hline \multirow{2}{*}{5} & 0.00 & -6.76 & 0.25 & -5.67 & 0.07 & -16.17 & -73.19 \\
\hline & 1.50 & -6.76 & -1.00 & -5.67 & -0.23 & -16.17 & -77.25 \\
\hline \multirow{2}{*}{6} & 0.00 & 4.50 & -1.81 & 5.43 & 0.00 & 20.77 & -100.00 \\
\hline & 0.50 & 4.50 & 1.30 & 5.43 & 0.00 & 20.77 & -100.00 \\
\hline \multirow{2}{*}{7} & 0.00 & -9.99 & -0.81 & -17.42 & 0.00 & 74.32 & -100.00 \\
\hline & 1.58 & -9.99 & 0.04 & -17.42 & 0.00 & 74.32 & -100.00 \\
\hline \multirow{2}{*}{8} & 0.00 & -0.52 & 0.72 & -0.19 & 0.00 & -63.85 & -100.00 \\
\hline & 0.50 & -0.52 & -0.54 & -0.19 & 0.00 & -63.85 & -100.00 \\
\hline \multirow{2}{*}{9} & 0.00 & 3.58 & -0.14 & 5.94 & 0.00 & 65.84 & -100.00 \\
\hline & 1.58 & 3.58 & 0.08 & 5.94 & 0.00 & 65.84 & -100.00 \\
\hline
\end{tabular}

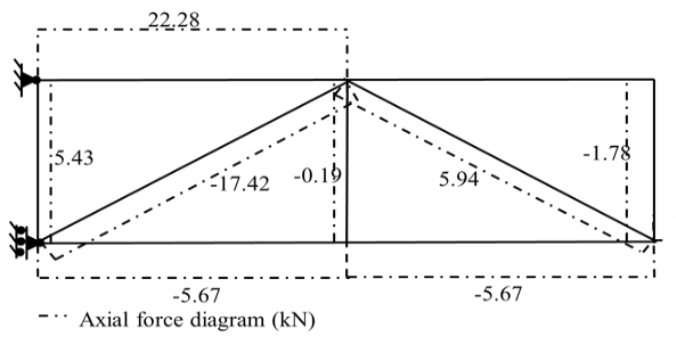

(a)

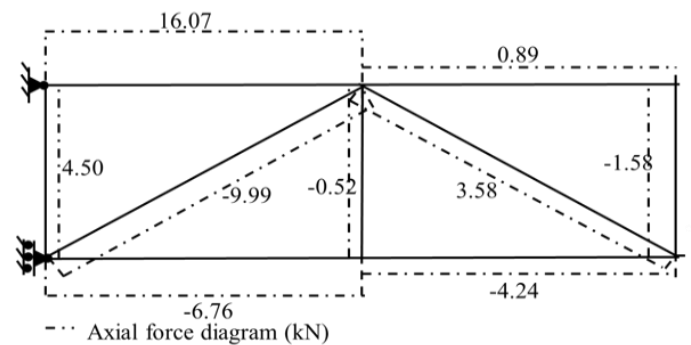

(b)

Figure 14. Diagrams of the axial force in the truss elements (a) truss with the rigid joint, and (b) truss with semi-rigid joint.

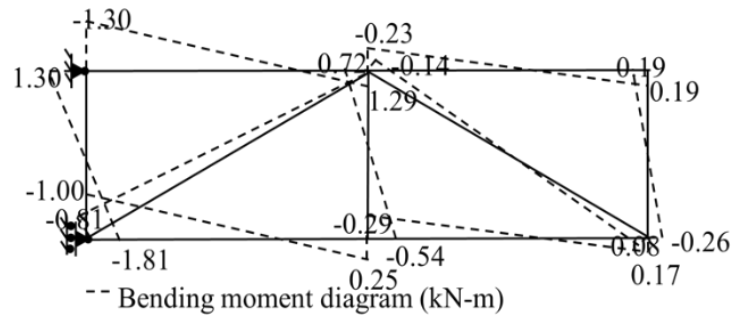

(a)

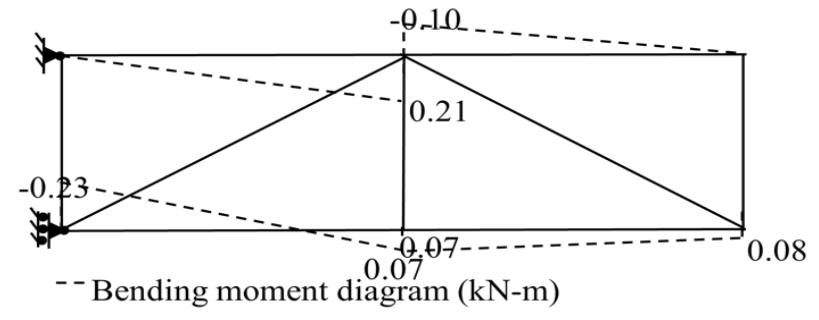

(b)

Figure 15. Diagrams of the bending moments in the truss elements (a) truss with the rigid joint, and (b) truss with semi-rigid joint. 


\section{Conclusion}

An elastic rotational stiffness equation for cold-formed steel connections was proposed in this study. Tests on a full-scale cantilever truss structure and bolt-moment connection tests, were conducted and the test results were verified by the 3D-finite elements modeling. The results from both tests show a good correlation with the finite element analysis results. The truss structure connection failure occurred with 5,571 $\mathrm{N}$ of ultimate load. Moreover, the bearing failure mode of the bolt holes was found in the bolt-moment connection specimens. The 2D-finite analysis was used to study the effect of the semi-rigid connection of the truss element in the structure. The proposed elastic rotational stiffness equation was applied to Richard and Abbott model [14] for simplifying the moment-rotation curve, and the equation was input into the 2D-finite analysis model. The analysis results showed that the axial forces in the truss elements increased by between $12.76 \%$ and $54.19 \%$ while some elements of the axial forces decreased by between $17.59 \%$ and $200 \%$. The bending moment decreased by $39.59-200 \%$. It was clearly demonstrated that the semi-rigid connection was more influential in the internal force in a truss structure. Therefore, semi-rigid connection analysis should be considered as the actual behavior of the structure, and applied in structural analysis for the best results.

\section{Conflict of interest}

The authors wish to confirm that there are no known conflicts of interest associated with this publication.

\section{Acknowledgment}

The authors wish to acknowledge the KURDI for providing funding support and BlueScope Lysaght (Thailand) Limited for material support. We also acknowledge the contribution of Mr. Roy I. Morien, of the Naresuan University Graduate School, for his assistance in editing English expressions and grammar in this paper.

\section{References}

[1] Lee, Y.H., Tan, C.S., Mohammad, S., Lim, J.B.P. and Johnston, R.: Numerical study of joint behaviour for top-seat flange cleat connection in cold-formed steel structures, Scientia Iranica B., 22 (2015), 4, 1554-1566.

[2] Cheng, B. and Wu, Z.: Finite Element Analysis on Tensile Stiffness of Cold-Formed Steel Bolted Connections, The Open Civil Engineering Journal, 9 (2015), 724-735.

[3] Jaghan, S. and Padmapriya, R: Behaviour of Bolted Cold Formed Steel Channel Tension Members, Asian Journal of Civil Engineering (Bhrc), 17 (2016), 1, 137-146.

[4] Padma Priya R.: Experimental Study on Behaviour of Bolted Cold-Formed Steel Angles under Tension, Asian Journal of Civil Engineering (Bhrc), 16(2015), 7, 967-975.

[5] Jaghan, S. and Padmapriya, R.: Behaviour of Bolted Cold Formed Steel Channel Tension Members, Asian Journal of Civil Engineering (Bhrc), 17(2016), 1, 137-146.

[6] Alomir, H., Neto, F, Luiz C.M. Vieira Jr., and Malite, M.: Strength and stiffness of cold-formed steel purlins with sleeved and overlapped bolted connections, Journal of Constructional Steel Research, 104 (2016), 45-53.

[7] Hassan, E. M., Mohammed H. S., and Mourad, A. S.: Numerical prediction of available rotation capacity of cold-formed steel beams, Journal of Constructional Steel Research, 128 (2017), 84-91.

[8] Igor Pešić, Domagoj Lanc, Goran Turkalj: Non-linear thermal buckling analysis of thin-walled beam structures, Engineering Review, 35 (2015), 3, 239-245.

[9] AISI-S100.: North American Specification for the Design of Cold-Formed Steel Structural Members, Washington DC, American Iron and Steel Institute (AISI), 2015.

[10] AS/NZS-4673.: Cold-Formed Stainless Steel Structures, Australian Standard/New Zealand Standard (AS/NZS), New Zealand, 2001.

[11] EN 1993-1-3.: Design of Steel Structures-Part 1.4: General Rules-Supplementary Rules for Stainless Steel, European Committee for Standardization (CEN), 2006.

[12] Dubina, D, and Zaharia, R.: Cold-Formed Steel Trusses with Semi-Rigid Joints, Thin Wall Structures, 29 (1997), 273-287 
[13] Dubina, D.: Structural analysis and design assisted by testing of cold-formed steel structures, Thin Wall Structures, 46 (2008) 741-764.

[14] Yu, W. K., Chung, K. F, and Wong, M. F.: Analysis of bolted moment connections in cold-formed steel beam-column sub-frames, Journal of Constructional Steel Research, 61 (2005) 1332-1352.

[15] Lim, J. B. P., and Nethercot, D. A.: Stiffness prediction for bolted moment connections between cold-formed steel members, Journal of Constructional Steel Research, 60 (2004) 85-107.

[16] Dundua, M., and Kemp, A. R.: Strength requirements of single cold-formed channels connected back-to-back, Journal of Constructional Steel Research, 62 (2006) 250-261.

[17] Zaharia, R., and Dubina, D.: Stiffness of joints in bolted connected cold-formed steel trusses, Journal of Constructional Steel Research, 62 (2006), 240-249

[18] Esfahanian, A., Mohamadi-Shooreh, M.R. and Mofid, M.: Assessment of the semi-rigid doubleangle steel connections and parametric analyses on their initial stiffness using FEM, Scientia Iranica A, 22 (2005), 6, 2033-2045.

[19] Zadanfarrokh, F., and Bryan, E. R.: Testing and design of bolted connections in cold-formed steel sections, In: Eleventh international specialty conference on cold-formed steel structures, University of Missouri- Rolla, St. Louis, Missouri, U.S.A, 1992.

[20] Bryan, E. R.: The design of bolted joints in cold-formed steel sections, Thin Wall Structures, 16 (1993), 239-262.

[21] Tan, S, Seah, L., and Li, Y.: Connections of sleeve joint purlin system, Structural Engineering and Mechanics, 13 (2002), 1-16.

[22] Wong, M. F., and Chung, K. F.: Structural behaviour of bolted moment connections in cold-formed steel beam-column sub-frames, Journal of Constructional Steel Research, 58 (2002), 2, 253-274.

[23] Richard, R. M., and Abbott, B. J.: Versatile elastic plastic stress-strain formula, Journal of Engineering Mechanics, 101, (1975), 4, 511-515.

[24] ASTM-A370-07b.: Standard test methods and definitions for mechanical testing of steel products, West Conshohocken: ASTM International, 2007.

[25] ASTM-A325M-94.: High strength bolts for structural steel joints [Metric], West Conshohocken: ASTM International, 1994.

[26] ANSYS.: ANSYS Mechanical APDL, version 14.5, ANSYS Academic Teaching Introductory, ANSYS, Inc., Canonsburg, Pennsylvania, USA, 2014.

[27] Ruipeng, L., Yunfeng, Z., and Le-Wei, T.: Numerical study of the cyclic load behavior of AISI $316 L$ stainless steel shear links for seismic fuse device, Frontiers of Structural and Civil Engineering, 8 (2014), 4, 414-426.

[28] CSI: SAP2000 V-15: Integrated finite element analysis and design of structures basic analysis reference manual, Berkeley, California (USA), Computers and Structures Inc., 2011.

[29] Konkong, N, Phuvoravan, K.: Parametric Study for Bearing Strength in Cold-Formed Steel Bolt Connections, International Review of Civil Engineering (I.RE.C.E.), 8 (2017), 3, 87-96.

[30] Konkong, N., and Phuvoravan, K.: An analytical method for determining the load distribution of single-column multibolt connection, Advances in Civil Engineering, 2017, doi:10.1155/2017/1912724. 